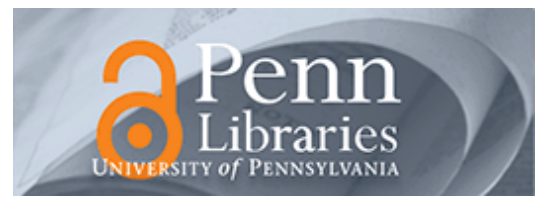

University of Pennsylvania

ScholarlyCommons

January 2002

\title{
Making Sense of Consensus: Responses to Engelhardt, Hester, Kuczewski, Trotter, and Zoloth
}

Jonathan D. Moreno

University of Pennsylvania, morenojd@mail.med.upenn.edu

Follow this and additional works at: https://repository.upenn.edu/bioethics_papers

\section{Recommended Citation}

Moreno, J. D. (2002). Making Sense of Consensus: Responses to Engelhardt, Hester, Kuczewski, Trotter, and Zoloth. Retrieved from https://repository.upenn.edu/bioethics_papers/23

Reprinted from Cambridge Quarterly of Healthcare Ethics, Volume 11, Issue 1, January 2002, pages 61-64.

Publisher URL: http://dx.doi.org/10.1017/S0963180102101083

NOTE: At the time of publication, author Jonathan D. Moreno was affiliated with the University of Virginia. Currently March 2007, he is a faculty member in the Department of Bioengineering at the University of Pennsylvania.

This paper is posted at ScholarlyCommons. https://repository.upenn.edu/bioethics_papers/23

For more information, please contact repository@pobox.upenn.edu. 


\title{
Making Sense of Consensus: Responses to Engelhardt, Hester, Kuczewski, Trotter, and Zoloth
}

\author{
Abstract \\ It has been a pleasure to read these papers and to contemplate their importance for what I believe to be a \\ useful and provocative prism though which to view the field of bioethics: the nature of moral consensus. \\ In my own most extended contribution to this literature, Deciding Together, I did not attempt to prescribe \\ so much as to understand the role of moral consensus in the practice of bioethics. At the end of the book, \\ I expressed the hope that it might help trigger an examination of bioethics and moral consensus. Though \\ a few others shared my interest at that time (in particular Tris Engelhardt, for whose early encouragement \\ I remain deeply grateful), with this set of stimulating papers the conversation has finally begun in earnest.

\section{Comments} \\ Reprinted from Cambridge Quarterly of Healthcare Ethics, Volume 11, Issue 1, January 2002, pages 61-64. \\ Publisher URL: http://dx.doi.org/10.1017/S0963180102101083 \\ NOTE: At the time of publication, author Jonathan D. Moreno was affiliated with the University of Virginia. \\ Currently March 2007, he is a faculty member in the Department of Bioengineering at the University of \\ Pennsylvania.
}


Special Section: Consensus in Bioethics:

Negotiating the Challenge of Moral Pluralism

\title{
Making Sense of Consensus: \\ Responses to Engelhardt, Hester, Kuczewski, Trotter, and Zoloth
}

\author{
JONATHAN D. MORENO
}

It has been a pleasure to read these papers and to contemplate their importance for what I believe to be a useful and provocative prism though which to view the field of bioethics: the nature of moral consensus. In my own most extended contribution to this literature, Deciding Together, ${ }^{1}$ I did not attempt to prescribe so much as to understand the role of moral consensus in the practice of bioethics. At the end of the book, I expressed the hope that it might help trigger an examination of bioethics and moral consensus. Though a few others shared my interest at that time (in particular Tris Engelhardt, for whose early encouragement I remain deeply grateful), with this set of stimulating papers the conversation has finally begun in earnest.

The study of bioethics as a practice has largely been neglected, as has the political character that must accompany human social practices. In this sense my use of the term "political" is not pejorative but appeals rather to a tradition of social philosophy that runs from Aristotle through Dewey and points to the ubiquity of human interaction in matters of moral import. Though Engelhardt is surely right that moral differences and political agendas can be obscured and that we should be wary of such obscurantism, I think he would also agree that there is no practical morality that does not have a political aspect, in the generic sense. That is precisely why consensus-oriented social practices that concern important matters like those with which bioethics concerns itself deserve scrutiny.

In general, I concur with Engelhardt's account of the "deconstruction" of professional independence in medical ethics (though the merely modern term "destruction" seems as apt), and the space that was therefore cleared for a new group of medical moral experts. But I think that, as a description of bioethical practice, Engelhardt sets the bar at an inaccurate height when he asserts that bioethicists have aspired to a "common secular morality." Rather, my view is that bioethics has succeeded in filling the space of moral expertise precisely by not setting their sights too far beyond cases and policies, or at least not beyond midlevel principles or maxims, thus easing the way toward consensus. Perhaps he is right that bioethics has "hoped to disclose a single canonical background moral consensus." Even with that goal unrealized, however, bioethics has achieved an astonishing level of credibility in a short time, given the small number of mutually legitimized "bioethicists" and the high stakes.

Unlike Engelhardt, I am more sanguine about the capacity of a community of moral inquirers to discern and subject to careful examination efforts that may exemplify a political agenda wrapped illicitly in the language of moral inquiry. 
Without concurring with the example he cites, the very fact that Engelhardt and I can engage in an assessment of such a case at least undermines his closing argument, one he promotes as a version of Marxian historical materialism. The argument has a surface appeal, yet like all such Marxian arguments, based on the notion of a "dominant material relationship" that expresses itself in all "ruling ideas," the argument is too strong. We are left unable to explain how all of us who are subjects of historical forces (including Engelhardt himself), can escape the dominant ideology and assume a critical posture toward the ruling ideas of our time, ideas like that of autonomy in bioethics (perhaps a disguised rationale for capitalist ethics dressed up as a moral principle). One explanation for this act of Engelhardtian transcendence might be that Texas is, as ever, a step ahead of the Zeitgeist.

Yet I do not see how social analysis can ever wholly dispense with the category of consensus. Thus Griffin Trotter's elegant account of his compromisebased Whiggism is doomed to be incomplete as a model of social decisionmaking. I can accept his stipulative definitions of strong, weak, and even the "doubly weak" consensus in terms of "correspondence between the verdicts of elite consensus-makers and the opinions of the population they represent." Of course, as Kuczewski notes, there can be stronger consensus within the "elite" (I guess that's us), than between them and the folks back home. I am not sure what Trotter thinks about this, but as for me, I am often satisfied to get whatever consensus I can.

Like Trotter and the other authors, I have been concerned about the complex relationship between professional bioethical deliberators and the wider society as an important problem for consensus theory in the practice of public bioethics. But in spite of Trotter's skepticism about my process view of consensus as "surreptitiously import[ing] many of the values that should be at issue in the debate about consensus," any representative decisionmaker who awaits a moment of stasis with the target population is unlikely to hold office for long. Those relationships are sure to be in flux, continuously negotiated, and perpetually uncomfortable, as they should be. Rather than surreptitious, I should say that the values inherent in such a relationship are worn on the sleeve of the process: mutual respect, openness, and candor being among them.

Trotter identifies himself as a bioethical Whig. According to his endnotes, Trotter especially identifies with that aspect of the Whig philosophy that favored parliamentary over executive authority. Rather than any "enforced content-rich moral vision," harmony is to be sought in "cooperation and consent." In the context of a deliberative body his formulation makes particular sense: "What will be done is, from the perspective of each party, the best possible approximation of what ought to be done, given the refractory posture of other parties" [emphasis in original]. No reason to worry here about illicit political agendas. In this description of "the art of the possible," politics is licit and evident as can be.

Thus I find it odd that Trotter accuses me of a "faux pas" in my account of compromise, an account modeled on "a negotiation between parties with differing interests. Each party enters the scene with a more or less fixed agenda" (Deciding Together, p. 45). Trotter pounces on "fixed" in this passage and rightly points out that persons with deeply held moral views may (and should) have "stable" values that should not be derided as "fixed." Indeed. But are we talking about moral deliberation or partisan (meaning interest-based) 
political negotiation? Now, Trotter uses the term "refractory," which according to another Whig, Daniel Webster, means stubborn or resistant. Given that, I should have thought not only that we were both talking about partisan politics but also that we share a notion of compromise that occurs between something like "fixed" or "stubborn" or "resistant" positions. If this is a faux pas, it is tout ensemble. On the other hand, if we're talking about moral deliberation, then I contend that stability is no substitute for a willingness to entertain the evidence or arguments for alternative points of view.

This is what I find finally incomplete about Trotter's Whiggism: How did the population represented by these trustees ever reach its "stable" moral scheme? Surely not by a process of compromise, which does not necessarily yield any deeply held values, but rather by some form of social agreement or consensus, much of it passive and in its particular beginnings probably lost in the now mainly mythical origins of the group.

Even Trotter's Whiggish bioethical trustees must appreciate that their parliamentary compromise is a modus operandi rather than a substantive resolution of the case or policy problem. In this respect Trotter's reference to The Federalist, No. 10, and Lincoln's continued protestations of his own Whiggishness, are striking in their irony. Madison's plea for the toleration of factions was mainly directed at the pro- and anti-slavery forces that threatened to tear apart the fledgling union of States. This case shows that no social arrangement in the face of moral controversy that is ungrounded in some substantive consensus, however modest, can long endure: Decades later, Lincoln vigorously (some would say ruthlessly) exploited executive power and circumvented Congress in the course of resolving the long-simmering crisis that no compromise could indefinitely manage. Sometimes moral consensus arrives only in retrospect and following the fixing of bayonets.

The papers of Micah Hester and Mark Kuczewski can be appreciated on their own terms once we clear away the central critique of bioethical consensus represented in Engelhardt and Trotter: that consensus among bioethicists serves a disguised agenda laden with unexamined values. Rather, Hester and Kuczewski seem to believe that bioethicists are no better than anyone else at covering up such shenanigans, even if they tried. Indeed, Kuczewski emphasizes precisely the opposite point: the failure of bioethicists to take a sufficiently political role in the debate about national health insurance. He makes a compelling case that, as citizens who have thought carefully about the matter, bioethicists have a civic obligation to make their thinking clear to their fellow citizens. Then Kuczewski examines how bioethical consensus on matters such as foregoing life-sustaining treatment and the conduct of biomedical research managed to get traction in public policy. I am impressed with his point that the key is to get below the surface of opinion to relatively stable values that are reflected in a social consensus and build the policy argument on those values.

Among the many features of Hester's paper with which I am in strong agreement is his discussion of the actual conditions of moral deliberation as problem oriented and messier than any decisionmaking model can be. In another writing ${ }^{2}$ I characterized such an account of bioethics as a naturalistic one, emphasizing the emergence of moral values from the rough-and-tumble of living conflict. My own experience in policy-oriented bioethics, especially in HIV/AIDS and research involving human subjects, has impressed me with the difficulty of work on actual problems and the fact that, as Hester and Kuc- 
zewski note, consensus is often far short of unanimity. With them, I would welcome more teamwork with social scientists and authorities on the narrative in efforts to understand the ways values are shaped, sustained, and modified.

Laurie Zoloth's communicative ethics is congenial to my naturalistic orientation; not surprising considering the later Wittgenstein has often been noted to enjoy a family resemblance to Dewey's empirical naturalism. Our differences are mainly ones of emphasis. In acknowledging the fruitfulness of viewing language as a form of life, care must be taken to avoid linguistic solipsism. If the agenda of a conversation is not set by problems that stem from nondiscursive experience, we are in danger of talking only to ourselves, precisely the illness that befell academic philosophy in the prebioethics days. So long as bioethics retains its orientation to cases and policies, in other words so long as it does not reduce to the moral philosophy of the life sciences, the fate of irrelevance is likely to be the least of our worries.

\section{Notes}

1. Moreno JD. Deciding Together: Bioethics and Moral Consensus. New York: Oxford University Press, 1995.

2. Moreno JD. Bioethics is a naturalism. In: McGee G, ed. Pragmatic Bioethics. Nashville, Tenn.: Vanderbilt University Press, 2000:5-17. 